\title{
Pragmatic difficulties in children with Specific Language Impairment
}

\author{
Comentado por: Telma Iacovino Monteiro ${ }^{1}$, Debora Maria Befi-Lopes ${ }^{2}$
}

Osman DM, Shohdi S, Aziz AA. Pragmatic difficulties in children with Specific Language Impairment. Int J Pediatr Otorhinolaryngol. 2010 Nov 22. doi:10.1016/j.ijporl.2010.10.028.

As crianças com Distúrbio Específico de Linguagem (DEL) frequentemente apresentam dificuldades pragmáticas que muitas vezes são esquecidas no momento da avaliação das habilidades de comunicação.

Via de regra, crianças com DEL costumam apresentar dificuldades em utilizar a linguagem de maneira efetiva e interagir com o outro: mostram dificuldades em processar as informações recebidas, concentram-se nos detalhes ao invés de extrair o significado central, utilizam tópicos de conversação inadequados, falam sobre temas irrelevantes ou sobre os quais o interlocutor não demonstra interesse, utilizam palavras atípicas, apresentam dificuldades em trocar o turno e não mantém o tópico da conversação, interrompem excessivamente o outro, apresentam respostas inapropriadas, mostram interpretação literal e apresentam déficit de cognição social.

A detecção precoce da incompetência pragmática das crianças com DEL pode permitir a identificação de risco de problemas de comportamento secundários a essas dificuldades e fornecer um marcador precoce para a detecção e/ou exclusão de distúrbios, tais como Autismo e Transtorno de Déficit de Atenção e Hiperatividade, Além disso, a maior parte das crianças com alterações pragmáticas apresentam dificuldades de processamento semântico, pois têm dificuldade em compreender o significado de palavras e frases, especialmente os abstratos e relacionados a sentimentos e emoções, e dificuldades com expressões idiomáticas, provérbios e gírias, aspectos fundamentais para a reabilitação de portadores de DEL.

$\mathrm{O}$ estudo buscou avaliar e esclarecer as dificuldades pragmáticas de um grupo de crianças com DEL comparadas com seus pares em desenvolvimento típico; para tanto, examinou os perfis pragmáticos de 60 crianças pareadas por idade e gênero, nativas do Cairo-Egito, falantes de Árabe (faixa etária de quatro a seis anos), todas com Extensão Média de Enunciado igual ou superior a cinco palavras. O grupo A incluiu 30 crianças com desenvolvimento típico de linguagem e o Grupo B incluiu 30 crianças com diagnóstico de DEL. Cada criança foi submetida à triagem das habilidades pragmáticas (Arabic Pragmatic Screening), que foi analisada por três examinadores para a

(1) Faculdade de Medicina, Universidade de São Paulo - USP - São Paulo (SP), Brasil.

(2) Curso de Fonoaudiologia da Faculdade de Medicina, Universidade de São Paulo - USP - São Paulo (SP), Brasil.

Endereço para correspondência: Debora Maria Befi-Lopes. R. Cipotânea, 51, Cidade Universitária, São Paulo (SP), Brasil, CEP: 05360-160. E-mail: dmblopes@usp.br obtenção dos escores médios e posterior análise estatística.

As habilidades pragmáticas analisadas neste estudo foram: parâmetros paralinguísticos não-verbais (frequência de ocorrência de contato de olho, uso adequado das posições do corpo, procura por objetos desejados, melodia da fala, volume de voz, expressões facial, respostas às saudações e manutenção da atenção); compreensão e descrição das funções dos objetos, habilidades conversacionais (iniciar e trocar turnos na conversação, fazer reparos na conversação, solicitar esclarecimentos e corrigir o outro); intencionalidade (manifestação de desejos, nomeação e comentários sobre objetos, respostas às perguntas, expressão de emoções) e habilidades narrativas (recontagem de descrições de figuras).

O estudo revelou que, para crianças falantes do Árabe, com idades entre quatro e seis anos, o escore total igual ou superior a 78.16/100 representa habilidades pragmáticas intactas. Para as habilidades paralinguísticas não-verbais o escore deve ser de 30.33/32; para funções do objeto o escore deve ser de 7.5/8; para as habilidades conversacionais o escore deve ser igual ou superior a 14.83/20; para intencionalidade o escore deve ser igual ou superior a 16.5/24 e para as habilidades narrativas o escore deve ser igual ou superior a 10.83/16.

O grupo controle revelou melhor desempenho do que o grupo DEL para as habilidades das funções dos objetos, conversacionais, narrativas, intencionalidade e pontuação total. As diferenças não foram significativas para as habilidades nãoverbais paralinguísticas, exceto para respostas às saudações e manutenção da atenção, onde o grupo controle apresentou melhores escores.

As diferenças entre os grupos para respostas às saudações e manutenção da atenção, podem ser atribuídas à timidez e à baixa auto-estima das crianças com DEL. As dificuldades em iniciar a conversação também parecem estar parcialmente relacionadas com a timidez e falta de autoconfiança, o que se evidenciou especialmente nas crianças com alterações fonológicas mais graves.

A dificuldade com as funções dos objetos parece estar relacionada com as dificuldades expressivas e não com a habilidade pragmática, podendo refletir dificuldades em acesso lexical e de conhecimento metalinguístico, o que ficou evidente nas crianças com DEL estudadas. Além disso, essas crianças apresentaram problemas de compreensão de perguntas e em descrever verbalmente emoções.

A maioria das crianças com DEL, ao recontar a descrição de figuras, tenderam a se concentrar em detalhes e não na ideia 
principal, apresentaram dificuldade na descrição, utilizando frases curtas, sem pronomes, marcadores de coesão e conjunções. Mais uma vez, isso pode ser parcialmente atribuído às dificuldades linguísticas, em vez de às dificuldades pragmáticas.

Crianças com DEL fazem inferências tardiamente, neste estudo não foram capazes de organizar sequencialmente os cartões de história, o que pode ser explicado pela limitada capacidade de organização e inferência visual.

As crianças em desenvolvimento típico, quando não conseguiram responder a um item, reformularam suas respostas ou procuraram a resposta, olhando o examinador em busca de aprovação. As crianças com DEL usaram mímica ou simplesmente responderam dizendo que não sabiam a resposta.

Pesquisas anteriores mostraram que crianças com DEL têm dificuldades para produzir narrativas orais, concordando com os resultados deste estudo; isto é, apresentaram mais erros de ordem de palavras e sentenças, indicando dificuldades com o processamento de informações linguísticas e dificuldades semânticas que refletem o conhecimento limitado e incapacidade de identificar o ponto-chave ou tópico em uma frase.
O presente estudo mostrou diferenças entre o desempenho pragmático de crianças com DEL e seus pares em desenvolvimento típico de linguagem, entretanto, destacam-se a natureza de tais déficits, muito mais relacionadas aos componentes linguísticos do que não linguísticos. Sendo assim, mesmo o estudo tendo sido realizado em crianças árabes, culturalmente diferentes das crianças ocidentais, os marcadores do DEL parecem confirmar a natureza do distúrbio. Tal fato vem confirmar os estudos recentes sobre a etiologia do quadro (possível marcador genético), uma vez que os achados são absolutamente concordantes com os apresentados pelas crianças ocidentais com o mesmo quadro. Além disso, por meio da compreensão de achados deste tipo é que vamos poder, em algum momento, entender a natureza específica dos quadros que acometem o desenvolvimento da linguagem. A novidade sobre a qual refletimos aqui é a concordancia de achados em culturas distintas em relação à mesma patologia da linguagem, o que reforça $\mathrm{a}$ universalidade do desenvolvimento e a possibilidade de estudos cross-linguísticos que a análise pragmática proporciona. 